\title{
Arachidonic Acid Metabolism and Its Implication on Head and Neck Cancer
}

\author{
Sittichai Koontongkaew ${ }^{1,2}$ and Kantima Leelahavanichkul ${ }^{1}$ \\ ${ }^{1}$ Faculty of Dentistry, Thammasat University, Pathumthani \\ ${ }^{2}$ Medicinal Herb Research Unit, Thammasat University, Pathumthani
}

Thailand

\section{Introduction}

Most of head and neck cancer (HNC) are squamous cell carcinoma. Recent advances in molecular biology have documented significant genetic differences between head and neck squamous cell carcinoma (HNSCC) cells and normal cells, leading to the development of potential new therapeutics and chemoprevention (Choi \& Myers, 2008). Historically, the association between inflammation and cancer has been recognized. More recently, a number of chronic inflammatory diseases have been shown to be associated with a variety of human cancers, including HNC (Conroy et al., 2010; Fitzpatrick \& Katz, 2010). The relationship between oral health and cancer has been examined for a number of specific cancer sites. Several studies have reported associations between periodontal disease or tooth loss and risk of oral, upper gastrointestinal, lung, and pancreatic cancer in different populations (Meyer et al., 2008). Cumulating evidences support the view that inflammatory mediators, some of that may downregulate DNA repair pathways directly or indirectly. Certain inflammatory mediators may affect on cell cycle checkpoints that result in the accumulation of random genetic alterations. These in turn lead to a genomically heterogenous population of expanding cells naturally selected for their ability to proliferate, invade and evade hose defenses (Colotta et al., 2009).

Molecular studies of the well-known relationship between polyunsaturated fatty acid metabolism and carcinogenesis provide novel molecular targets for cancer chemoprevention and treatments. Several classes of agents have shown promise as chemopreventive agents, including the nonsteroidal anti-inflammatory drugs (NSAIDs), which posses a valid scientific basis for the prevention of multiple cancers, including HNC. Because NSAIDs are wellaccepted inhibitors of cyclooxygenase (COX) and prostaglandin (PG) production, research work initially focused on COX-and PG-dependent mechanism of NSAIDs actions. Polyunsaturated fatty acid, including arachidonic and linoleic acids, can enhance tumorigenesis (Shureiqi \& Lippman, 2001). Aberrant arachidonic acid (AA) metabolism, especially COX-2 and 5-lipoxygenase (5-LOX) pathways, are activated during oral carcinogenesis, and can be targeted for cancer prevention (el-Hakim \& Langdon, 1991). Recently, we found that inhibition of AA metabolism caused a decrease in HNSCC cell invasion and matrix metalloproteinase (MMP) activities. Our findings suggest the contributory roles of COX and LOX in HNC development and progression (Koontongkaew et al., 2010). 
This review will briefly summarize the implication of AA metabolism in HNC. We will discuss what are known of COX and LOX in tumorigenesis of HNC. Possible mechanisms of action of COX and LOX and potential roles for AA inhibitors in the prevention and therapy of this cancer will be documented in this review.

\section{Arachidonic acid cascade}

AA is a long chain polyunsaturated fatty acid containing 20 carbons. It can be stored in membrane phospholipids and released from nuclear envelop or plasma membrane by cytosolic phospholipase A2 (cPLA2), either constitutively or in respond to a variety of cell specific stimuli, including growth factors, hormones, cytokines, signaling molecules, or cell trauma. Free AA can be subsequently metabolized by three key enzymes, COX, LOX, or cytochrome P450 (CYP450) to generate lipid mediators, eicosanoids, which involved in various biological function, inflammation regulation, and more recently, tumor progression (Funk, 2001; Wang et al., 2007; Hyde \& Missailidis, 2009). COX metabolism generates prostanoids, including prostaglandins (PGs) and thromboxanes (TXs). LOX generates leukotrienes (LTs), lipoxin (LXs) and hepoxillins (HOs). CYP450 metabolic pathway gives a family of lipoxygenase-like hydroeicosatetraenoic acids (HETEs), epoxyeicosatrienoic acids (EETs) and $\omega$-HETEs (Capdevila et al., 2000).

\subsection{The COX pathway}

In the COX pathway, COX first oxidized AA to form prostaglandin G2 (PGG 2 ), and is then metabolized into an intermediate prostaglandin $\mathrm{H}_{2}\left(\mathrm{PGH}_{2}\right)$ by peroxidase activity (Figure 1 ). $\mathrm{PGH}_{2}$ is an unstable endoperoxide, which is catalyzed to five primary prostanoids, including $\mathrm{PGD}_{2}, \mathrm{PGE}_{2}, \mathrm{PGF}_{2 \mathrm{a}}, \mathrm{PGI}_{2}$ and thromboxane $\mathrm{A}_{2}$ by specific synthases.

Three isoforms of COX have been identified, COX-1, COX-2 and COX-3 (Williams et al., 1999; Wang et al., 2007). COX-1 and COX-2 are similar in structure and catalytic activity. Both enzymes have the same molecular weight and share a $61 \%$ amino acid sequence homology. COX-3 is the splice variants of COX-1, which retains intron 1 and has a frameshift mutation (Wang et al., 2007). COX-3 was constitutively highest expressed in the cerebral cortex and heart tissue (Chandrasekharan et al., 2002). COX-1 is constitutively expressed in almost all tissues and resident inflammatory cells. It generates PGs that control homeostasis. COX-2 is normally undetectable. Constitutive COX-2 expression is well recognized in brain, kidney and the female reproductive tract. However, COX-2 is the most important regulator in the respond to inflammation and many types of cancers. COX-2 can be induced by multiple cytokines and growth factors, via activation of transcription factors that act on the promoter region, including TATA box, and NF-IL6 motif, two AP-2 sites, three Sp1 sites, two NF-kB sites, a CRE motif and an E-box (Park et al., 2006).

The PGEs subclass, including cytosolic PGE synthase (cPGEs) and membrane-bound PGE synthases (mPGEs), is also involved in inflammation and carcinogenesis. Once the various PGs are synthesized, they are exported into the extracellular microenvironment and bind to the specific G-protein coupled receptors (GPCRs) that can be activated by autocrine and paracrine fashions in the tumor microenvironment (Sugimoto \& Narumiya, 2007). 


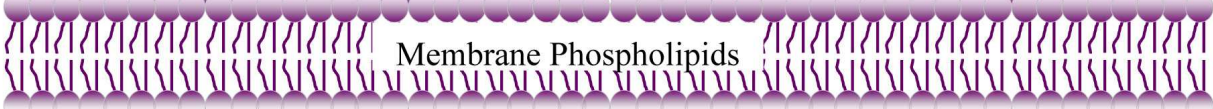

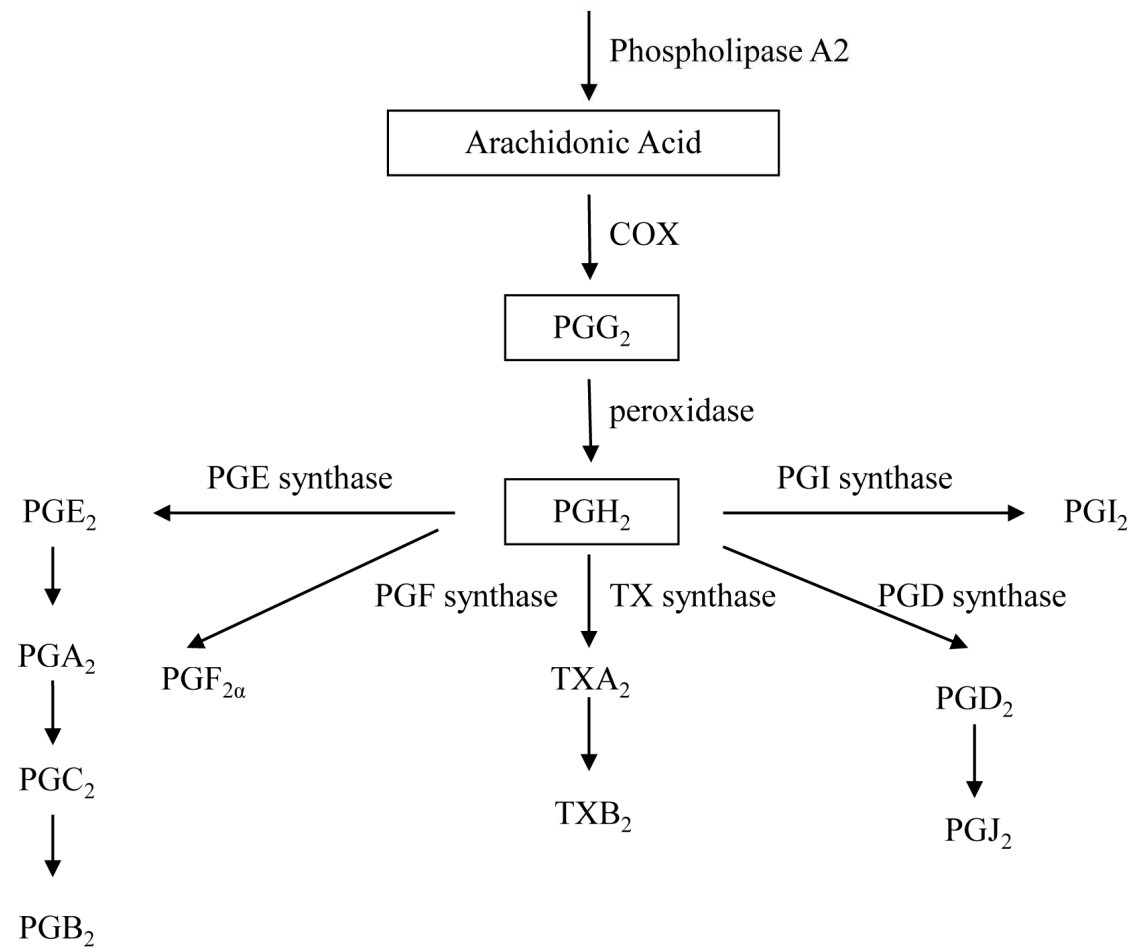

Fig. 1. Main products and enzymes of the COX pathway. COX: cyclooxygenase; PG: prostaglandin; TX: thromboxane.

\section{COX and HNC}

In the last decade inflammation and cancer had been linked together as biomarkers and novel targets of cancer therapy in a large number of cancers, including HNC. Overexpressions of COX-2 and prostanoids have been shown in various forms of human cancers, including $\mathrm{HNC}$, and they can be linked with cancer progression and metastasis (Lee et al., 2001; Krysan et al., 2004; Huh et al., 2009). COX-2 expression was correlated with shorter survival in non-small cell lung cancer and poor survival in prostate cancer and gliomas patients (Khuri et al., 2001; Shono et al., 2001; Khor et al., 2007). Upregulation of COX-2 has been reported in human tissues and cell lines as well as in serum of patients with HNC. The increased levels of COX-2 were associated with the risk of tobacco- and betel nutrelated cancers, advance clinical stage, survival and lymph node metastasis (Tang et al., 2003; Molinolo et al., 2007; Chiang et al., 2008; Husvik et al., 2009; Saba et al., 2009; Kapoor et al., 2010; Mittal et al., 2010). In addition, $\mathrm{PGE}_{2}$ receptors are widely expressed in a variety of HNSCC cell lines as well as in tumor tissues (Abrahao et al., 2010). 
Several studies showed the effects of COX inhibitors on cancer cell proliferation, invasion and proliferation, invasion and metastasis. Selective COX-2 inhibitors decreased viability, invasion and adhesion of HNSCC cells by down-regulated MMP-2, MMP-9 and vascular endothelial growth factor (VEGF) secretion (Kim et al., 2010; Koontongkaew et al., 2010; Li et al., 2010). Moreover, suppression of COX-2 expression by small RNAs reduced cancer cell proliferation and invasion by decreased VEGF production (Park et al., 2010; Wang et al., 2010). Selective COX-1 inhibitor also decreased cancer cell proliferation (Koontongkaew et al., 2010). However, little is known about the molecular mechanism of the COX-2 pathway in the regulation of HNSCC cell growth. Molecular mechanism of cell apoptosis by COX2/ $\mathrm{PGE}_{2}$ through phosphatidylinositol 3-kinase (PI3K)/AKT pathway has been suggested in human epidermoid carcinoma cells (Agarwal et al., 2009).

COX-2 is expressed in tumor neovasculature as well as in tumor tissues. The proangiogenic factors of COX-2 are $\mathrm{TXA}_{2}, \mathrm{PGI}_{2}$ and $\mathrm{PGE}_{2}$. Selective inhibitor of COX-2 has been shown to suppress angiogenesis in vitro and in vivo by reduced VEGF production (Williams et al., 2000). This suggests a role of COX in the process of angiogenesis, which might have an effect in HNSCC cell proliferation.

\subsection{COX and ERK pathway}

Upregulation of epidermal growth factor receptor (EGFR) has been suggested as a major pathway involved in HNSCC progression (Le Tourneau et al., 2007; Molinolo et al., 2009). Activation of EGFR has been shown to induce increased COX-2 expression in various normal and cancer cell lines, including HNSCC cells. However, the signaling pathway involved in COX-2 via EGFR varies depending on the type of cells and inducers, but the ras/ raf/ mitogen-activated protein kinases (MAPKs) signaling pathways mainly contribute to both increased transcriptional and posttranscriptional controls. On the other hand, COX-2 could induce transactivation or upregulate EGFR expression (Choe et al., 2005; Husvik et al., 2009).

Selective COX-2 inhibitors have been shown to decrease $\mathrm{PGE}_{2}$ production in vitro and in vivo (Hoshikawa et al., 2009; Abrahao et al., 2010). This implies that upregulated $\mathrm{PGE}_{2}$ in tumor microenvironment by COX-2 overexpression may promote the growth of HNSCC cells in an autocrine and/or paracrine effects by acting on widely expressed $\mathrm{PGE}_{2}$ receptors in HNSCC cells. Additionally, p53, a tumor suppressor, play an inhibitory role in AA metabolism. It downregulates COX-2 expression and leads to tumor cell apoptosis (Subbaramaiah et al., 1999).

\subsection{COX and PI3K/AKT pathway}

The PI3K/AKT pathway plays critical roles in the control of cancer cell survival and apoptosis in many cancers, including HNC (Jiang \& Liu, 2008; Cohen et al., 2011). It has been recognized that protein kinase $\mathrm{B}(\mathrm{Akt} / \mathrm{PKB})$ activity is implicated in K-Ras-induced expression of COX-2, and the mRNA stability of COX-2 partially depends on the activation of AKT (Sheng et al., 2001). Indomethacin, a NSAID, has been found to induce apoptosis in renal cell carcinoma cells by activating AKT and MAPK signaling (Ou et al., 2007). Celecoxib, a selective COX-2 inhibitor, had been shown to induce apoptosis through (PI3K)/AKT and the COX-2 signaling pathway in various cancers, including non-small cell 
lung carcinoma, prostate and gastric cancers (Kulp et al., 2004; Zhu et al., 2004; Fan et al., 2006). In HNC, however, the mechanism of COX-2 upregulation is not fully understood. There was reported that COX alone did not effect on pEGFR, pERK1/2 and pAKT. However, inhibition of combination of COX and EGFR reduced the AKT activities of HNSCC cells (Chen et al., 2004b).

\subsection{COX and tumor invasion}

It is well documented that COX inhibitors reduce cancer cell migration, cell adhesion and tumor invasiveness (Lin et al., 2002). Increased invasiveness has been associated with activation of MMPs. MMPs are a family of proteolytic enzymes linked to several malignant properties of a variety of tumor cells, including HNSCC cells (Rosenthal \& Matrisian, 2006). Therefore, it is possible that COX-2 enhances tumor cell invasion through the upregulated MMP activities. To date, however, a few studies have investigated the importance of COX-2 in modulating the invasive properties of HNSCC cells. Recently, we found that COX-1 and COX-2 inhibitors reduced cell viability, MMP-2 and MMP-9 activities, and in vitro invasion of primary and metastatic HNSCC cells (Koontongkaew et al., 2010). Our findings are consistent with other studies that demonstrated the inhibitory effects of COX inhibitors on MMP activities in breast (Larkins et al., 2006), prostate (Attiga et al., 2000), colon (Ishizaki et al., 2006) and lung cancer cells (Karna \& Palka, 2002). Regarding the role of COX-2 in the metastasis and invasion of HNSCC cells, the precise mechanism remains obscure, but a decrease of COX-2 dependent $\mathrm{PGE}_{2}$ may downregulate MMP production through $\mathrm{PGE}_{2}$ receptors (Dohadwala et al., 2002).

\section{Inhibition of COX}

NSAIDs, non-selective inhibitors for COX, are over-the-counter drugs and widely use as analgesics, anti-inflammations, antipyretic and chemoprevention in cardiovascular diseases and other disorders. Experimental tumor model studies show that NSAIDs impair the growth and development of HNSCC, indicating potential as a chemopreventive agent (Cornwall et al., 1983; Lin et al., 2002; Mohan \& Epstein, 2003). Moreover, both non-selective and selective of COX prevented 4-nitroquinoline- oxide (NQO)-induced tumorigenesis in rats (McCormick et al., 2010). Regular use of aspirin has been shown to reduce the risk of colon cancer (Dube et al., 2007). Celecoxib is approved for the chemoprevention of colon cancer in patients with familial adenomatous polyposis. This COX-2 inhibitor has also been shown to reduce the incidence of various cancers in vivo (Grosch et al., 2006). To date, however, no definitive conclusion on the effect of NSAIDs/aspirin use on the risk of HNSCC is well documented (Wilson et al., 2011). Although NSAIDs or aspirin may have protective effect on HNSCC, further large-scale studies are required.

Selective COX-2 inhibitors were reported to enhance treatment responds to radiotherapy or combination of radiotherapy and chemotherapy, suggesting that the inhibitors can improve the response of various cancers to conventional cancer therapies (Liao et al., 2003; Komaki et al., 2004). To date, several concurrent clinical trial studies of HNC are using a combination of standard treatment with a selective COX-2 inhibitor and the others, such as EGFR inhibitor, which has been shown to improve survival in patients with non-small cell lung cancer (Fidler et al., 2008). A combination of EGFR-selective tyrosine kinase inhibitor with a COX- 
2 inhibitor (celecoxib) induced cell cycle arrest and apopotosis in HNSCC cells. The combination showed strong reduction of EGFR, ERK1/2 and AKT activations (Chen et al., 2004b). The phase 1 clinical trial, using a combination of an EGFR inhibitor (erlotinib), a selective COX-2 inhibitor (celecoxib) and reirradiation showed a feasible and clinically active regimen for recurrent HNC patients (Kao et al., 2011). During and after radiotherapy in combination with celecoxib, significant decrease of the plasma levels of VEGF were observed in patients with advanced HNC who had high COX-2 expression in their tumor tissues (Halamka et al., 2011).

\section{The LOX pathway}

In human cells, generally, four types of LOXs have been identified, namely 5-, 12- and 15-LOX1 and LOX-2. Collectively, they catalyze the oxygenation of AA into hydroperoxyeicosatetraenoic acids (HPETEs) (Figure 2). Ultimately, this is followed by their conversion to their corresponding hydroeicosatetraenoic acids (HETEs), leading to the formation of LTs, LXs and HOs. The metabolism of linoleic acid preferentially results in the formation of hydroxyloctadecadienoic acids (HODEs). 5-LOX catalyzes the first step in the oxygenation of AA to produce 5-HPETE, and the subsequent metabolism of 5-HPETE to 5HETE and LTs. LTs belong to a key group of pro-inflammatory mediators that are synthesized from AA via the 5-LOX pathway. The activity of 5-LOX leads to the formation of unstable LTA4, which can be converted into LTB4 or cysteinyl LTs (LTC4, LTD4 and LTE4) Platelettype 12-LOX ( $p 12-\mathrm{LOX})$ exclusively uses AA released from glycerol-phospholipid pools to synthesize 12S-HPETE and 12S-HETE, whereas leukocyte-type 12-LOX can also synthesize 15S-HETE and 12S-HETE. In addition to leukocytes and platelets, the expression of 12-LOX isozymes has been observed in various types of cells, including smooth muscle cells, endothelial cells and keratinocytes. 15-lipoxygeases (15-LOX) can be subdivided into two isoforms, namely 15-LOX-1 and 15-LOX-2. 15-LOX-1 is mainly expressed in reticulocytes, eosinophils and airway epithelial cells, as well as in macrophages. In terms of enzymatic characteristics, 15-LOX-1 preferentially metabolizes linoleic acid primarily to 13S-HODE, but also metabolizes AA to 15S-HETE. 15-LOX-2, on the other hand, converts AA to 15S-HETE and poorly metabolizes linoleic acid (Romano \& Claria, 2003).

The products of LOX metabolism represent either intermediary products such as HPETE, which are transformed enzymatically into secondary products, including LTs, LXs, HOs and HETEs, which can act as signaling molecules in their own right or give rise to the production of reactive oxygen species (ROS). Signaling of LOX-derived products can occur through either G protein coupled cell-surface receptors, in the case of LOs and LTs, or through activation of nuclear receptors such as peroxisome proliferator activated receptors (PPARs) in the case of HETEs and HODEs (Pidgeon et al., 2007).

\section{LOX and HNC}

Early tumorigenesis studies in animals demonstrated the contributory roles of AA and linoleic acid in tumorigenesis. Various LOX products have been linked to tumorigenesis in vitro and also in vivo in animal models. In addition, the modulation of LOX metabolism has anticarcinogenic effects on tumor development. Therefore, it suggests that LOX modulation has been targeted for developing anticarcinogenic agents (Shureiqi \& Lippman, 2001). 


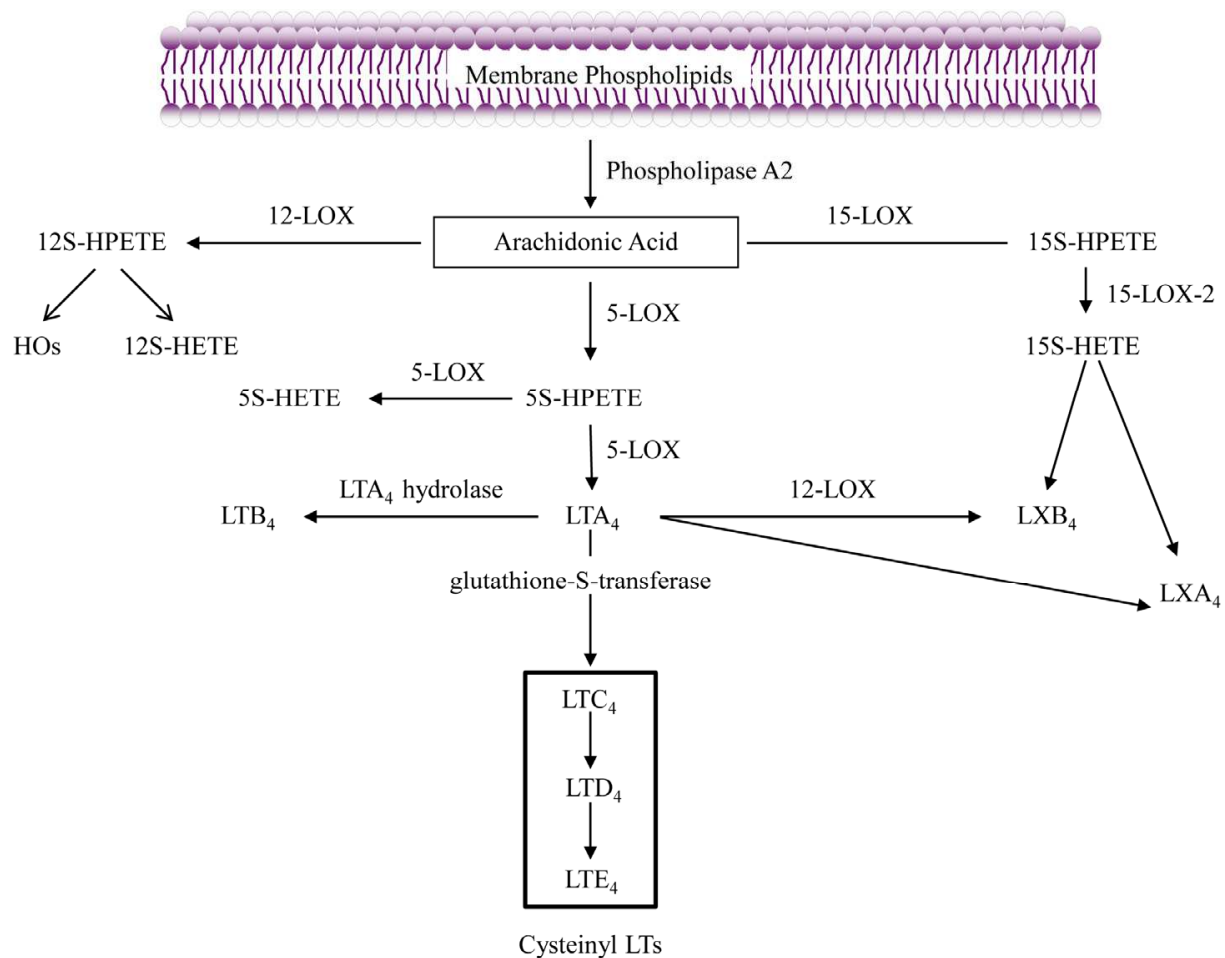

Fig. 2. Main products and enzymes of the LOX pathway. LOX: lipoxygenase; HPETE: hydroperoxyeicosatetraenoic acid; HETE: hydroxyeisatetraenoic acid; HOs: Hepoxillins; LXs: lipoxins; LT: leukotriene.

5-LOX, 12-LOX, 15-LOX-1 and 15-LOX-2 were detected in HNSCC cell lines derived from primary and metastatic tumors. Therefore, it is not surprised that LOX metabolites, including 5-HETE, 12-HETE, 15-HETE and 13-HODE were found in primary and metastatic HNSCC cells. However, there was no correlation between LOX isoforms and their metabolites in HNSCC cells (Schroeder et al., 2004). The level of LTB4, a metabolite of the 5LOX pathway, was found to be higher in oral cancer lesions in human and hamsters (elHakim et al., 1990; Li et al., 2005). This enzyme was also upregulated in other cancers, including prostate (Gupta et al., 2001), pancreatic (Hennig et al., 2002), colon (Ohd et al., 2003) and esophageal cancers (Chen et al., 2004a). Previous studies in 7,12dimethylbenz[a]anthracene (DMBA)-induced hamster oral cancer demonstrated overexpression of 5-LOX in the stromal inflammatory cells and epithelial cells at the early stages of oral squamous cell carcinogenesis. Moreover, zileuton, a specific 5-LOX inhibitor and celecoxib (a specific COX-2 inhibitor), either alone or in combination, had an inhibitory effect on the incidence of oral tumor in DMBA-treated animals. Zileuton seems even more effective than celecoxib. These findings suggest that the 5-LOX pathway of AA metabolism plays an important role in inflammation-associated oral cancer (Li et al., 2005).

Recently, studies in the mouse model showed that the expression of 5-LOX and COX-2 was increased in dysplasia and squamous cell carcinoma of 4-nitroquinoline-1-oxide (4NQO)- 
treated tongues, and further enhanced by ethanol. Fewer tumors were induced in Alox5-/mice, as were cell proliferation, inflammation, and angiogenesis in the tongue, as compared with Alox5+/+ mice. COX-2 expression was induced by ethanol in knockout mice, while 5LOX and LTA4H expression and LTB4 biosynthesis were dramatically reduced. Moreover, ethanol enhanced expression and nuclear localization of 5-LOX and stimulated LTB4 biosynthesis in human tongue squamous cell lines. These findings suggest that the activation of the 5-LOX pathway of AA metabolism involves in oral carcinogenesis (Guo et al., 2011).

Inhibition of AA metabolism (COX-2 and 5-LOX) by curcumin has also been suggested as a key mechanism of its anticarcinogenic action in DMBA-induced hamster oral carcinoma (Li et al., 2002; Bengmark, 2006). Zyflamed, a product containing 10- concentrate herbal extracts significantly reduced infiltration of inflammatory cells, incidence of hyperplasia and dysplastic lesions, cell proliferation as well as number of tumors in the DMBA-induced hamster cheek pouch model. Furthermore, it was shown that zyflamed reduced LTB4 formation compared with that of the control (Yang et al., 2008).

In a long-term carcinogenesis study, topical application of LTB4 enhanced oral carcinogenesis by increasing the incidence and sizes of tumors. LTB4 inhibitors significantly inhibited oral carcinogenesis, and the anticarcinogenesis as such correlated with reduced levels of LTB4 (Sun et al., 2006). An in-vitro study demonstrated that addition of LTB4 to RBL-1 cells, a rat leukemia cell line expressing high levels of 5-LOX, could counteract the inhibition of cell proliferation produced by a LOX inhibitor (zyflamed) (Yang et al., 2008).

LOX products were indentified in human mixed saliva and in saliva fractions obtained from a parotid or submandibular gland. In glandular saliva, only linoleic acid was detected at levels of $20-30 \mathrm{ng} / \mathrm{ml}$. In contrast, mixed saliva showed a linoleic acid concentration of around $300 \mathrm{ng} / \mathrm{ml}$, AA levels of around $30 \mathrm{ng} / \mathrm{ml}$, HODE levels between 5 and $10 \mathrm{ng} / \mathrm{ml}$, and HETE levels up to $25 \mathrm{ng} / \mathrm{ml}$. By far the most abundant HETE was 12-HETE, and incubation experiments with AA showed the presence of a substantial 12-LOX activity in human mixed saliva, but not in saliva fractions. Investigating mixed saliva and glandular saliva of patients with squamous cell carcinoma in the upper aerodigestive tract and of controls; most patients showed elevated levels of free AA and elevated HETE levels. Besides a moderate increase in 12-HETE levels, markedly elevated concentrations of 5-HETE and 15HETE were observed for the carcinoma patients. Therefore, it is proposed that the level of free AA, and the quantitative HETE profile appear to be good markers for the inflammatory processes occurring in the oral mucosa and in saliva in response to the development of squamous cell carcinoma (Metzger et al., 1995).

\subsection{Molecular mechanisms of LOX-mediated HNC development}

As mentioned above, substantial evidence supports a functional role for LOX-catalyzed AA metabolism in HNC development. Pharmacologic and natural inhibitors of LOX have been shown to suppress carcinogenesis and tumor growth in a number of experimental models. In recent years participation of LOX in the regulation of cell proliferation, apoptosis and angiogenesis has emerged. Many cell pathways are involved in the process by which cells choose between growth arrest, apoptosis or survival. The crosstalk of LOX derived products 
with different growth factor receptor-induced signaling cascades is involved in the stimulation of tumor cell growth.

The aberrant activation of multiple signaling pathways, including EGFR, ras, NFkB, STAT, Wnt/ $\beta$-catenin, TGF- $\beta$ and PI3K/AKT were observed in HNSCC (Molinolo et al., 2009). Oncogenic events in HNC associated with abnormal activation of the PI3K/AKT pathway include mutations, allelic loss, or the promoter methylation of the negative regulator phosphatase and tensin homolog (PTEN) (Cohen et al., 2011). LOX metabolites may exert their biological effects in an intracrine manner, through the activation of transcription factors of the PPAR family, or they may interact with specific trans-membrane G proteincouple cell surface receptors in an autocrine or paracrine manner (Pidgeon et al., 2007). LOX metabolites may involve in ERK1/2, PI3K/AKT cascade, and STAT signaling pathways in HNSCC cells (Pidgeon et al., 2007). PTEN may be oxidized and inactivated during AA metabolism in cancer cells. Oxidation of PTEN resulted in a decrease of its phosphatase activity, favoring increased PI-3, 4, 5-trisphosphate $\left(\mathrm{PIP}_{3}\right)$ production, activation of AKT and phosphorylation of downstream AKT targets. Such activation leads to cell cycle induction during HNC development (Covey et al., 2007; Jiang \& Liu, 2008).

Tumor growth does not only depend on increased cell proliferation but also on prolonged cell survival through the inhibition of cell death or apoptosis. LOX inhibition has been shown to induce apoptosis in cancer cells (Lepage et al., 2010). LOX metabolites may enhance cancer cell survival through an increase in Bcl-2. In addition, they can upregulate the p-ERK and p-AKT levels, suggesting the involvement of ERK and AKT pathways in the LOX-mediated regulation of growth in cancer cells (Agarwal et al., 2009). However, it was found that metabolism of AA by 5-LOX activity promotes survival of cancer cells via signaling through $\mathrm{PKC} \varepsilon$, a pro-survival serine/threonine kinase which is not dependent on the AKT and ERK-pathway (Sarveswaran et al., 2011).

In addition to its role in neoplastic transformation, 5-LOX and its AA metabolite had shown to be involved in angiogenesis. 12S-HETE has been shown to be a mitogenic factor for microvascular endothelial cells and stimulates endothelial cell migration. Moreover, 12SHETE has an ability to induce the expression of VEGF, an important proangiogenic factor, at both protein and promoter levels (Pidgeon et al., 2007).

However, little is known about the role of LOX in HNC cell metastasis. The process of tumor invasion by cancer cells involves degradation of the underlying basement membrane, which largely made up of collagen IV. MMP-2 and MMP-9 showed substrate specificity toward type IV and V collagen and a number of studies have demonstrated a strong correlation between MMP expression and metastatic potential (Rosenthal \& Matrisian, 2006). Recently, our findings demonstrated the inhibitory effects of NDGA (nordihydroguaiaretic acid, the selective LOX inhibitor) and ETYA (5, 8, 11, 14eicosatetraynoic acid, the COX and LOX inhibitor) on cell proliferation, MMP activity and invasion in primary and metastatic HNSCC cells (Koontongkaew et al., 2010). It is possible that LOX inhibitors activate PPAR $\gamma$ activity and subsequent reduction in MMP-9 signaling (Hyde \& Missailidis, 2009).

The ability of tumor cells to generate 12S-HETE is positively correlated to their metastatic potential and the increased expression of $p 12$-LOX enhanced the metastatic potential of cancer cells. Moreover, 12S-HETE has been found to modulate multi steps of the metastatic 
process encompassing tumor cell and endothelial cell interactions, tumor cell motility, proteolysis and invasion (Furstenberger et al., 2006). Moreover, LOX may promote tumor cell migration through FAK (focal adhesion kinase) activation (Navarro-Tito et al., 2008).

It should be noted that the role of LOX in HNC development is thought to be more complex, compared with that of COX because 6 LOX genes have been identified in human and different profiles of LOX were found in studies on human tumor biopsies and experimentally induced animal tumor models. The inverse expression pattern of individual LOX isoenzymes in normal versus malignant tissues and the biological effects of the corresponding LOX products propose the important role of dynamic balance among LOX isoenzymes in tumorigenesis. It has been shown a dynamic balance among LOX shifting toward the procarcinogenic 5- and $p 12$-LOX and away from anticarcinogenic LOXs such as 15-LOX-1, 15-LOX-2, 8-LOX and epidermal-type 12-LOX (e12-LOX) during prostate and colon cancer development (Menna et al., 2010). However, at present little is known about modulation of carcinogenesis through pro-and anticarcinogenic LOX isoforms in HNC development and progression.

\section{Converging pathways of COX and LOX in HNC}

The AA-metabolizing enzymes are overexpressed during animal and human carcinogenesis and AA metabolites such as $\mathrm{PGE}_{2}$, 5-HETE and LTB4 had been implicated in HNC development. COX-2 and 5-LOX play important roles in inflammation and inflammationassociated tumorigenesis. It is evident that COX and LOX display similarities in expression and functions in HNC. In particular, the COX-2 and 5-LOX pathways are activated together during inflammation, and blocking one pathway may activate the other. It was shown that inhibition of COX-2 might lead to a shunt of AA metabolism towards the LT pathway in HNC. Suppressing $\mathrm{PGE}_{2}$ levels by a COX-2 inhibitors, celecoxib, leads to an increase in the activity of 5-LOX, 12-LOX and 15-LOX-2 and results in the increase of their products, including, 5-HETE, 12-HETE and 15-HETE (Schroeder et al., 2004). A study in the mouse model of HNC, demonstrated an increase of LTB4 in tumor tissues in mice treated with $\mathrm{PGE}_{2}$. In contrast, LTB4 could not decrease tumor tissue levels of $\mathrm{PGE}_{2}$ (Scioscia et al., 2000). Therefore, simultaneous blocking of each enzyme may be required to achieve substantial elevation in free AA levels and prevent the shunting of metabolism to another active pathway.

Taken together, COX-2 and 5-LOX may have redundant function in HNC pathobiology. First, COX-2 and 5-LOX enhance tumor cell proliferation. Second, both COX-2 and 5-LOX are proangiogenic with a convergent targeting on VEGF, FGF and MMPs. Third, COX-2 as well as 5-LOX inhibitors, arrest cell cycle progression and induce apoptotic cell death in HNSCC cells. Fourth, both COX-2 and 5-LOX enhance HNSCC cell invasion and tumor metastasis. In addition, active COX2 and 5-LOX are localized in the nucleus, and they may function as endogenous ligands for nuclear receptors such as the PPARs (Menna et al.; Romano \& Claria, 2003) (Figure 3).

\section{Future prospects and conclusions}

The summarized findings contained in this review support the contributory role of chronic inflammation in the pathogenesis of HNC. A hallmark of the inflammatory process is the 
synthesis of inflammatory cytokines and AA metabolites. Two major AA metabolic routes, i.e., the COX and LOX pathways control the biosynthesis of eicosanoid. COX-derived eicosanoids comprise PG and TXA 2 , whereas HPETE and LTs are products of LOXcatalyzed arachidonic acid metabolism. In HNC, COX-2 and LOX are coexpressed and upregulated in tumor cell lines, experimentally induced animal tumor models and human tumor biopsies. Currently, the underlying mechanisms for the tumorigenic effects of COX and LOX remain somewhat undefined. A number of studies of HNC have suggested the involvement of COX-2 and/ or 5-LOX in tumor cell proliferation, apoptosis, angiogenesis and metastasis.

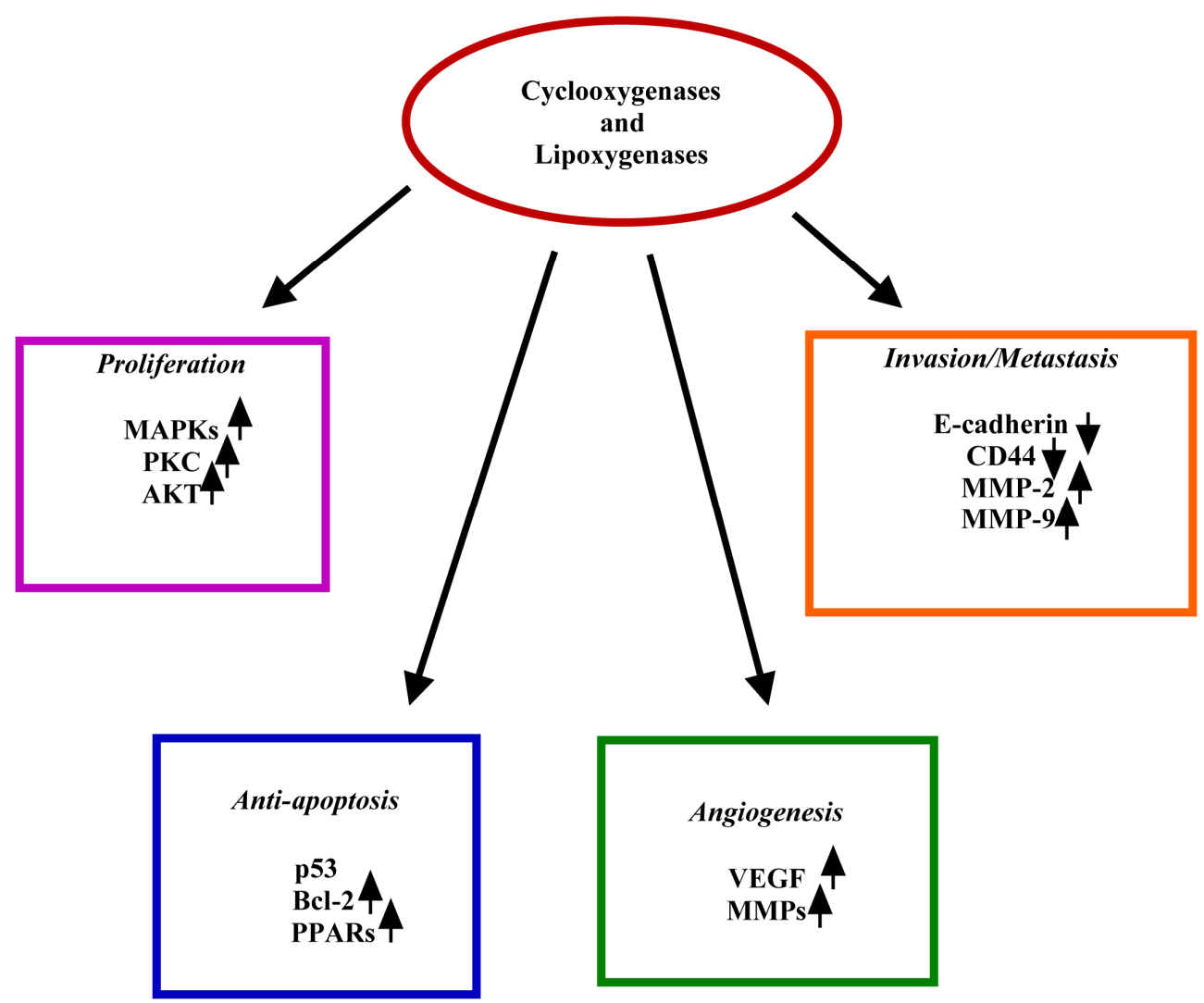

Fig. 3. Effects of COXs and LOXs on tumerigenesis. Both COXs and LOXs stimulate proliferation, inhibit apoptosis, induce angiogenesis, and enhance invasion and metastasis in cancer cells. MAPKs: mitogen activated protein kinases; PKC: protein kinase C; Bcl-2: Bcell lymphoma2; PPARs: peroxisome proliferator-activated receptor; VEGF: vascular endothelial growth factor; MMP: matrix metalloproteinase.

COX and/ or LOX inhibitors in many instances demonstrate potent anticancer effects. Manipulation of AA metabolism, therefore, represents a promising approach to develop HNC therapy. However, in spite of extensive research in COX and LOX inhibitors, their 
combined use for chemoprevention is still in its development stage. Further investigations are indeed necessary to develop appreciate chemopreventive strategies in HNC. First, the mechanism by which COX and LOX pathways are deregulated, interacted with each other, or contribute to head and neck tumorigenesis must be more clarified. Second, more clinical studies are critical to evaluate the effectiveness of COX and LOX inhibitors and to understand their mechanisms of action a single agent and in combination in HNC, specifically. Eventually, possible drug toxicity from a combined use must be evaluated over the long term.

\section{References}

Abrahao AC, Castilho RM, Squarize CH, Molinolo AA, dos Santos-Pinto D, Jr. \& Gutkind JS (2010) A role for COX2-derived PGE2 and PGE2-receptor subtypes in head and neck squamous carcinoma cell proliferation. Oral Oncol 46, 880-887.

Agarwal S, Achari C, Praveen D, Roy KR, Reddy GV \& Reddanna P (2009) Inhibition of 12LOX and COX-2 reduces the proliferation of human epidermoid carcinoma cells (A431) by modulating the ERK and PI3K-Akt signalling pathways. Exp Dermatol 18, 939-946.

Attiga FA, Fernandez PM, Weeraratna AT, Manyak MJ \& Patierno SR (2000) Inhibitors of prostaglandin synthesis inhibit human prostate tumor cell invasiveness and reduce the release of matrix metalloproteinases. Cancer Res 60, 4629-4637.

Bengmark S (2006) Curcumin, an atoxic antioxidant and natural NFkB, cyclooxygenase-2, lipooxygenase, and inducible nitric oxide synthase inhibitor: a shield against acute and chronic diseases. JPEN J Parenter Enteral Nutr 30, 45-51.

Capdevila JH, Falck JR \& Harris RC (2000) Cytochrome P450 and arachidonic acid bioactivation. Molecular and functional properties of the arachidonate monooxygenase. J Lipid Res 41, 163-181.

Chandrasekharan NV, Dai H, Roos KL, Evanson NK, Tomsik J, Elton TS \& Simmons DL (2002) COX-3, a cyclooxygenase-1 variant inhibited by acetaminophen and other analgesic/antipyretic drugs: cloning, structure, and expression. Proc Natl Acad Sci U S A 99, 13926-13931.

Chen X, Wang S, Wu N, Sood S, Wang P, Jin Z, Beer DG, Giordano TJ, Lin Y, Shih WC, Lubet RA \& Yang CS (2004a) Overexpression of 5-lipoxygenase in rat and human esophageal adenocarcinoma and inhibitory effects of zileuton and celecoxib on carcinogenesis. Clin Cancer Res 10, 6703-6709.

Chen Z, Zhang X, Li M, Wang Z, Wieand HS, Grandis JR \& Shin DM (2004b) Simultaneously targeting epidermal growth factor receptor tyrosine kinase and cyclooxygenase-2, an efficient approach to inhibition of squamous cell carcinoma of the head and neck. Clin Cancer Res 10, 5930-5939.

Chiang SL, Chen PH, Lee CH, Ko AM, Lee KW, Lin YC, Ho PS, Tu HP, Wu DC, Shieh TY \& Ko YC (2008) Up-regulation of inflammatory signalings by areca nut extract and role of cyclooxygenase-2 -1195G>a polymorphism reveal risk of oral cancer. Cancer Res 68, 8489-8498.

Choe MS, Zhang X, Shin HJ, Shin DM \& Chen ZG (2005) Interaction between epidermal growth factor receptor- and cyclooxygenase 2-mediated pathways and its 
implications for the chemoprevention of head and neck cancer. Mol Cancer Ther 4, 1448-1455.

Choi S \& Myers JN (2008) Molecular pathogenesis of oral squamous cell carcinoma: implications for therapy. J Dent Res 87, 14-32.

Cohen Y, Goldenberg-Cohen N, Shalmon B, Shani T, Oren S, Amariglio N, DratvimanStorobinsky O, Shnaiderman-Shapiro A, Yahalom R, Kaplan I \& Hirshberg A (2011) Mutational analysis of PTEN/PIK3CA/AKT pathway in oral squamous cell carcinoma. Oral Oncol, 47, 946-950.

Colotta F, Allavena P, Sica A, Garlanda C \& Mantovani A (2009) Cancer-related inflammation, the seventh hallmark of cancer: links to genetic instability. Carcinogenesis 30, 1073-1081.

Conroy H, Mawhinney L \& Donnelly SC (2010) Inflammation and cancer: macrophage migration inhibitory factor (MIF)--the potential missing link. QJM 103, 831-836.

Cornwall H, Odukoya O \& Shklar G (1983) Oral mucosal tumor inhibition by ibuprofen. J Oral Maxillofac Surg 41, 795-800.

Covey TM, Edes K \& Fitzpatrick FA (2007) Akt activation by arachidonic acid metabolism occurs via oxidation and inactivation of PTEN tumor suppressor. Oncogene 26, 5784-5792.

Dohadwala M, Batra RK, Luo J, Lin Y, Krysan K, Pold M, Sharma S \& Dubinett SM (2002) Autocrine/paracrine prostaglandin E2 production by non-small cell lung cancer cells regulates matrix metalloproteinase-2 and CD44 in cyclooxygenase-2dependent invasion. J Biol Chem 277, 50828-50833.

Dube C, Rostom A, Lewin G, Tsertsvadze A, Barrowman N, Code C, Sampson M \& Moher D (2007) The use of aspirin for primary prevention of colorectal cancer: a systematic review prepared for the U.S. Preventive Services Task Force. Ann Intern Med 146, 365-375.

el-Hakim IE \& Langdon JD (1991) Arachidonic acid cascade and oral squamous cell carcinoma. Clin Otolaryngol Allied Sci 16, 563-573.

el-Hakim IE, Langdon JD, Zakrzewski JT \& Costello JF (1990) Leukotriene B4 and oral cancer. Br J Oral Maxillofac Surg 28, 155-159.

Fan XM, Jiang XH, Gu Q, Ching YP, He H, Xia HH, Lin MC, Chan AO, Yuen MF, Kung HF \& Wong BC (2006) Inhibition of Akt/PKB by a COX-2 inhibitor induces apoptosis in gastric cancer cells. Digestion 73, 75-83.

Fidler MJ, Argiris A, Patel JD, Johnson DH, Sandler A, Villaflor VM, Coon Jt, Buckingham L, Kaiser K, Basu S \& Bonomi P (2008) The potential predictive value of cyclooxygenase-2 expression and increased risk of gastrointestinal hemorrhage in advanced non-small cell lung cancer patients treated with erlotinib and celecoxib. Clin Cancer Res 14, 2088-2094.

Fitzpatrick SG \& Katz J (2010) The association between periodontal disease and cancer: a review of the literature. J Dent 38, 83-95.

Funk CD (2001) Prostaglandins and leukotrienes: advances in eicosanoid biology. Science 294, 1871-1875.

Furstenberger G, Krieg P, Muller-Decker K \& Habenicht AJ (2006) What are cyclooxygenases and lipoxygenases doing in the driver's seat of carcinogenesis? Int J Cancer 119, 2247-2254. 
Grosch S, Maier TJ, Schiffmann S \& Geisslinger G (2006) Cyclooxygenase-2 (COX-2)independent anticarcinogenic effects of selective COX-2 inhibitors. J Natl Cancer Inst 98, 736-747.

Guo Y, Wang X, Zhang X, Sun Z \& Chen XL (2011) Ethanol promotes chemically induced oral cancer in mice through activation of the 5-lipoxygenase pathway of arachidonic acid metabolism. Cancer Prev Res (Phila), 4, 1863-1872.

Gupta S, Srivastava M, Ahmad N, Sakamoto K, Bostwick DG \& Mukhtar H (2001) Lipoxygenase-5 is overexpressed in prostate adenocarcinoma. Cancer 91, 737-743.

Halamka M, Cvek J, Kubes J, Zavadova E, Kominek P, Horacek J, Dusek L \& Feltl D (2011) Plasma levels of vascular endothelial growth factor during and after radiotherapy in combination with celecoxib in patients with advanced head and neck cancer. Oral Oncol 47, 763-767.

Hennig R, Ding XZ, Tong WG, Schneider MB, Standop J, Friess H, Buchler MW, Pour PM \& Adrian TE (2002) 5-Lipoxygenase and leukotriene $\mathrm{B}(4)$ receptor are expressed in human pancreatic cancers but not in pancreatic ducts in normal tissue. Am J Pathol 161, 421-428.

Hoshikawa H, Goto R, Mori T, Mitani T \& Mori N (2009) Expression of prostaglandin E2 receptors in oral squamous cell carcinomas and growth inhibitory effects of an EP3 selective antagonist, ONO-AE3-240. Int J Oncol 34, 847-852.

Huh JW, Kim HR, Lee JH \& Kim YJ (2009) Comparison of cyclooxygenase-2 and CD44 mRNA expression in colorectal cancer and its relevance for prognosis. Virchows Arch 454, 381-387.

Husvik C, Khuu C, Bryne M \& Halstensen TS (2009) PGE2 production in oral cancer cell lines is COX-2-dependent. J Dent Res 88, 164-169.

Hyde CA \& Missailidis S (2009) Inhibition of arachidonic acid metabolism and its implication on cell proliferation and tumour-angiogenesis. Int Immunopharmacol 9, 701-715.

Ishizaki T, Katsumata K, Tsuchida A, Wada T, Mori Y, Hisada M, Kawakita H \& Aoki T (2006) Etodolac, a selective cyclooxygenase-2 inhibitor, inhibits liver metastasis of colorectal cancer cells via the suppression of MMP-9 activity. Int J Mol Med 17, 357362.

Jiang BH \& Liu LZ (2008) PI3K/PTEN signaling in tumorigenesis and angiogenesis. Biochim Biophys Acta 1784, 150-158.

Kao J, Genden EM, Chen CT, Rivera M, Tong CC, Misiukiewicz K, Gupta V, Gurudutt V, Teng M \& Packer SH (2011) Phase 1 trial of concurrent erlotinib, celecoxib, and reirradiation for recurrent head and neck cancer. Cancer 117, 3173-3181.

Kapoor V, Singh AK, Dey S, Sharma SC \& Das SN (2010) Circulating cycloxygenase-2 in patients with tobacco-related intraoral squamous cell carcinoma and evaluation of its peptide inhibitors as potential antitumor agent. J Cancer Res Clin Oncol 136, 17951804.

Karna E \& Palka JA (2002) Inhibitory effect of acetylsalicylic acid on metalloproteinase activity in human lung adenocarcinoma at different stages of differentiation. Eur J Pharmacol 443, 1-6.

Khor LY, Bae K, Pollack A, Hammond ME, Grignon DJ, Venkatesan VM, Rosenthal SA, Ritter MA, Sandler HM, Hanks GE, Shipley WU \& Dicker AP (2007) COX-2 
expression predicts prostate-cancer outcome: analysis of data from the RTOG 92-02 trial. Lancet Oncol 8, 912-920.

Khuri FR, Wu H, Lee JJ, Kemp BL, Lotan R, Lippman SM, Feng L, Hong WK \& Xu XC (2001) Cyclooxygenase-2 overexpression is a marker of poor prognosis in stage I nonsmall cell lung cancer. Clin Cancer Res 7, 861-867.

Kim YY, Lee EJ, Kim YK, Kim SM, Park JY, Myoung H \& Kim MJ (2010) Anti-cancer effects of celecoxib in head and neck carcinoma. Mol Cells 29, 185-194.

Komaki R, Liao Z \& Milas L (2004) Improvement strategies for molecular targeting: Cyclooxygenase-2 inhibitors as radiosensitizers for non-small cell lung cancer. Semin Oncol 31, 47-53.

Koontongkaew S, Monthanapisut P \& Saensuk T (2010) Inhibition of arachidonic acid metabolism decreases tumor cell invasion and matrix metalloproteinase expression. Prostaglandins Other Lipid Mediat 93, 100-108.

Krysan K, Merchant FH, Zhu L, Dohadwala M, Luo J, Lin Y, Heuze-Vourc'h N, Pold M, Seligson D, Chia D, Goodglick L, Wang H, Strieter R, Sharma S \& Dubinett S (2004) COX-2-dependent stabilization of survivin in non-small cell lung cancer. FASEB J 18, 206-208.

Kulp SK, Yang YT, Hung CC, Chen KF, Lai JP, Tseng PH, Fowble JW, Ward PJ \& Chen CS (2004) 3-phosphoinositide-dependent protein kinase-1/Akt signaling represents a major cyclooxygenase-2-independent target for celecoxib in prostate cancer cells. Cancer Res 64, 1444-1451.

Larkins TL, Nowell M, Singh S \& Sanford GL (2006) Inhibition of cyclooxygenase-2 decreases breast cancer cell motility, invasion and matrix metalloproteinase expression. BMC Cancer 6, 181-192.

Le Tourneau C, Faivre S \& Siu LL (2007) Molecular targeted therapy of head and neck cancer: review and clinical development challenges. Eur J Cancer 43, 2457-2466.

Lee LM, Pan CC, Cheng CJ, Chi CW \& Liu TY (2001) Expression of cyclooxygenase-2 in prostate adenocarcinoma and benign prostatic hyperplasia. Anticancer Res 21, 12911294.

Lepage C, Liagre B, Cook-Moreau J, Pinon A \& Beneytout JL (2010) Cyclooxygenase-2 and 5lipoxygenase pathways in diosgenin-induced apoptosis in HT-29 and HCT-116 colon cancer cells. Int J Oncol 36, 1183-1191.

Li N, Chen X, Liao J, Yang G, Wang S, Josephson Y, Han C, Chen J, Huang MT \& Yang CS (2002) Inhibition of 7,12-dimethylbenz[a]anthracene (DMBA)-induced oral carcinogenesis in hamsters by tea and curcumin. Carcinogenesis 23, 1307-1313.

Li N, Sood S, Wang S, Fang M, Wang P, Sun Z, Yang CS \& Chen X (2005) Overexpression of 5-lipoxygenase and cyclooxygenase 2 in hamster and human oral cancer and chemopreventive effects of zileuton and celecoxib. Clin Cancer Res 11, 2089-2096.

Li WZ, Huo QJ, Wang XY \& Xu F (2010) Inhibitive effect of celecoxib on the adhesion and invasion of human tongue squamous carcinoma cells to extracellular matrix via down regulation of MMP-2 expression. Prostaglandins Other Lipid Mediat 93, 113119.

Liao Z, Milas L, Komaki R, Stevens C \& Cox JD (2003) Combination of a COX-2 inhibitor with radiotherapy or radiochemotherapy in the treatment of thoracic cancer. Am J Clin Oncol 26, S85-91. 
Lin DT, Subbaramaiah K, Shah JP, Dannenberg AJ \& Boyle JO (2002) Cyclooxygenase-2: a novel molecular target for the prevention and treatment of head and neck cancer. Head Neck 24, 792-799.

McCormick DL, Phillips JM, Horn TL, Johnson WD, Steele VE \& Lubet RA (2010) Overexpression of cyclooxygenase- 2 in rat oral cancers and prevention of oral carcinogenesis in rats by selective and nonselective COX inhibitors. Cancer Prev Res (Phila) 3, 73-81.

Menna C, Olivieri F, Catalano A \& Procopio A (2010) A Lipoxygenase inhibitors for cancer prevention: promises and risks. Curr Pharm Des 16, 725-733.

Metzger K, Angres G, Maier H \& Lehmann WD (1995) Lipoxygenase products in human saliva: patients with oral cancer compared to controls. Free Radic Biol Med 18, 185194.

Meyer MS, Joshipura K, Giovannucci E \& Michaud DS (2008) A review of the relationship between tooth loss, periodontal disease, and cancer. Cancer Causes Control 19, 895907.

Mittal M, Kapoor V, Mohanti BK \& Das SN (2010) Functional variants of COX-2 and risk of tobacco-related oral squamous cell carcinoma in high-risk Asian Indians. Oral Oncol 46, 622-626.

Mohan S \& Epstein JB (2003) Carcinogenesis and cyclooxygenase: the potential role of COX2 inhibition in upper aerodigestive tract cancer. Oral Oncol 39, 537-546.

Molinolo AA, Amornphimoltham P, Squarize CH, Castilho RM, Patel V \& Gutkind JS (2009) Dysregulated molecular networks in head and neck carcinogenesis. Oral Oncol 45, 324-334.

Molinolo AA, Hewitt SM, Amornphimoltham P, Keelawat S, Rangdaeng S, Meneses Garcia A, Raimondi AR, Jufe R, Itoiz M, Gao Y, Saranath D, Kaleebi GS, Yoo GH, Leak L, Myers EM, Shintani S, Wong D, Massey HD, Yeudall WA, Lonardo F, Ensley J \& Gutkind JS (2007) Dissecting the Akt/mammalian target of rapamycin signaling network: emerging results from the head and neck cancer tissue array initiative. Clin Cancer Res 13, 4964-4973.

Navarro-Tito N, Robledo T \& Salazar EP (2008) Arachidonic acid promotes FAK activation and migration in MDA-MB-231 breast cancer cells. Exp Cell Res 314, 3340-3355.

Ohd JF, Nielsen CK, Campbell J, Landberg G, Lofberg H \& Sjolander A (2003) Expression of the leukotriene D4 receptor CysLT1, COX-2, and other cell survival factors in colorectal adenocarcinomas. Gastroenterology 124, 57-70.

Ou YC, Yang CR, Cheng CL, Raung SL, Hung YY \& Chen CJ (2007) Indomethacin induces apoptosis in 786-O renal cell carcinoma cells by activating mitogen-activated protein kinases and AKT. Eur J Pharmacol 563, 49-60.

Park JY, Pillinger MH \& Abramson SB (2006) Prostaglandin E2 synthesis and secretion: the role of PGE2 synthases. Clin Immunol 119, 229-240.

Park SW, Kim HS, Hah JH, Kim KH, Heo DS \& Sung MW (2010) Differential effects between cyclooxygenase-2 inhibitors and siRNA on vascular endothelial growth factor production in head and neck squamous cell carcinoma cell lines. Head Neck 32, 1534-1543.

Pidgeon GP, Lysaght J, Krishnamoorthy S, Reynolds JV, O'Byrne K, Nie D \& Honn KV (2007) Lipoxygenase metabolism: roles in tumor progression and survival. Cancer Metastasis Rev 26, 503-524. 
Romano M \& Claria J (2003) Cyclooxygenase-2 and 5-lipoxygenase converging functions on cell proliferation and tumor angiogenesis: implications for cancer therapy. FASEB J 17, 1986-1995.

Rosenthal EL \& Matrisian LM (2006) Matrix metalloproteases in head and neck cancer. Head Neck 28, 639-648.

Saba NF, Choi M, Muller S, Shin HJ, Tighiouart M, Papadimitrakopoulou VA, El-Naggar AK, Khuri FR, Chen ZG \& Shin DM (2009) Role of cyclooxygenase-2 in tumor progression and survival of head and neck squamous cell carcinoma. Cancer Prev Res (Phila) 2, 823-829.

Sarveswaran S, Thamilselvan V, Brodie C \& Ghosh J (2011) Inhibition of 5-lipoxygenase triggers apoptosis in prostate cancer cells via down-regulation of protein kinase Cepsilon. Biochim Biophys Acta, 1813, 2108-2117.

Schroeder CP, Yang P, Newman RA \& Lotan R (2004) Eicosanoid metabolism in squamous cell carcinoma cell lines derived from primary and metastatic head and neck cancer and its modulation by celecoxib. Cancer Biol Ther 3, 847-852.

Scioscia KA, Snyderman CH, D'Amico F, Comsa S, Rueger R \& Light B (2000) Effects of arachidonic acid metabolites in a murine model of squamous cell carcinoma. Head Neck 22, 149-155.

Sheng H, Shao J \& Dubois RN (2001) K-Ras-mediated increase in cyclooxygenase 2 mRNA stability involves activation of the protein kinase B1. Cancer Res 61, 2670-2675.

Shono T, Tofilon PJ, Bruner JM, Owolabi O \& Lang FF (2001) Cyclooxygenase-2 expression in human gliomas: prognostic significance and molecular correlations. Cancer Res $61,4375-4381$.

Shureiqi I \& Lippman SM (2001) Lipoxygenase modulation to reverse carcinogenesis. Cancer Res 61, 6307-6312.

Subbaramaiah K, Altorki N, Chung WJ, Mestre JR, Sampat A \& Dannenberg AJ (1999) Inhibition of cyclooxygenase-2 gene expression by p53. J Biol Chem 274, 1091110915.

Sugimoto Y \& Narumiya S (2007) Prostaglandin E receptors. J Biol Chem 282, 11613-11617.

Sun Z, Sood S, Li N, Ramji D, Yang P, Newman RA, Yang CS \& Chen X (2006) Involvement of the 5-lipoxygenase/leukotriene A4 hydrolase pathway in 7,12dimethylbenz[a]anthracene (DMBA)-induced oral carcinogenesis in hamster cheek pouch, and inhibition of carcinogenesis by its inhibitors. Carcinogenesis 27, 19021908.

Tang DW, Lin SC, Chang KW, Chi CW, Chang CS \& Liu TY (2003) Elevated expression of cyclooxygenase (COX)-2 in oral squamous cell carcinoma--evidence for COX-2 induction by areca quid ingredients in oral keratinocytes. J Oral Pathol Med 32, 522529.

Wang MT, Honn KV \& Nie D (2007) Cyclooxygenases, prostanoids, and tumor progression. Cancer Metastasis Rev 26, 525-534.

Wang YH, Wu MW, Yang AK, Zhang WD, Sun J, Liu TR \& Chen YF (2010) COX-2 Gene increases tongue cancer cell proliferation and invasion through VEGF-C pathway. Med Oncol, doi:10.1007/s12032-12010-19737-12033

Williams CS, Mann M \& DuBois RN (1999) The role of cyclooxygenases in inflammation, cancer, and development. Oncogene 18, 7908-7916. 
Williams CS, Tsujii M, Reese J, Dey SK \& DuBois RN (2000) Host cyclooxygenase-2 modulates carcinoma growth. J Clin Invest 105, 1589-1594.

Wilson JC, Anderson LA, Murray LJ \& Hughes CM (2011) Non-steroidal anti-inflammatory drug and aspirin use and the risk of head and neck cancer: a systematic review. Cancer Causes Control 22, 803-810.

Yang P, Sun Z, Chan D, Cartwright CA, Vijjeswarapu M, Ding J, Chen X \& Newman RA (2008) Zyflamend reduces LTB4 formation and prevents oral carcinogenesis in a 7,12-dimethylbenz[alpha]anthracene (DMBA)-induced hamster cheek pouch model. Carcinogenesis 29, 2182-2189.

Zhu J, Huang JW, Tseng PH, Yang YT, Fowble J, Shiau CW, Shaw YJ, Kulp SK \& Chen CS (2004) From the cyclooxygenase-2 inhibitor celecoxib to a novel class of 3phosphoinositide-dependent protein kinase-1 inhibitors. Cancer Res 64, 4309-4318. 


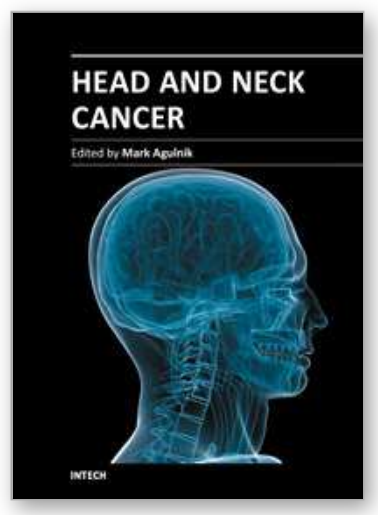

\author{
Head and Neck Cancer \\ Edited by Dr. Mark Agulnik
}

ISBN 978-953-51-0236-6

Hard cover, 440 pages

Publisher InTech

Published online 14, March, 2012

Published in print edition March, 2012

Head and Neck Cancer provides an interesting and comprehensive overview of all aspects of head and neck cancer including overviews of the disease, basic science aspects pertaining to the disease, diagnosis, treatment and outcomes for patients with this disease. The chapters written by world renowned experts cover the entire discipline of head and neck oncology and include discussions of regional disparity is, advances in basic science understanding, advances in her radiotherapy, chemotherapy and targeted agents as well as a focus on reconstruction, prostheses, and aspects of quality of life and health outcomes. The book is designed to be both practical and comprehensive for every physician treating his complex disease.

\title{
How to reference
}

In order to correctly reference this scholarly work, feel free to copy and paste the following:

Sittichai Koontongkaew and Kantima Leelahavanichkul (2012). Arachidonic Acid Metabolism and Its Implication on Head and Neck Cancer, Head and Neck Cancer, Dr. Mark Agulnik (Ed.), ISBN: 978-953-51-0236-6, InTech, Available from: http://www.intechopen.com/books/head-and-neck-cancer/arachidonic-acid-metabolism-and-itsimplication-on-head-and-neck-cancer

\section{INTECH}

open science | open minds

\section{InTech Europe}

University Campus STeP Ri

Slavka Krautzeka 83/A

51000 Rijeka, Croatia

Phone: +385 (51) 770447

Fax: +385 (51) 686166

www.intechopen.com

\section{InTech China}

Unit 405, Office Block, Hotel Equatorial Shanghai

No.65, Yan An Road (West), Shanghai, 200040, China

中国上海市延安西路65号上海国际贵都大饭店办公楼405单元

Phone: +86-21-62489820

Fax: +86-21-62489821 
(C) 2012 The Author(s). Licensee IntechOpen. This is an open access article distributed under the terms of the Creative Commons Attribution 3.0 License, which permits unrestricted use, distribution, and reproduction in any medium, provided the original work is properly cited. 